\title{
A Educação Ambiental através do Ecoturismo: o diferencial das atividades de contato dirigido com a natureza
}

\author{
Zysman Neiman $^{1}$ \\ Andréa Rabinovich ${ }^{2}$
}

Resumo: Este artigo apresenta os resultados da análise de 107 viagens de Ecoturismo ao Parque Estadual Turístico do Alto Ribeira com o objetivo de verificar o papel do contato dirigido e intensificado com a natureza no processo de Educação Ambiental. Foram realizadas reuniões com Grupos Focais alguns dias após o regresso, de modo a verificar as opiniões pessoais sobre as viagens e a empreender uma análise quantiqualitativa destas através da elaboração do Discurso do Sujeito Coletivo (DSC), comparando-as com atividades similares realizadas por outros agentes, mas com caráter mais informal, característica marcante do mercado de Ecoturismo. Os resultados apontam diferenças significativas nas percepções dos entrevistados, reforçando a hipótese de que o Ecoturismo deve promover um contato mais intenso com a natureza para se tornar um efetivo instrumento de Educação Ambiental.

Palavras-chave: Ecoturismo, Educação Ambiental, Percepção Ambiental.

Abstract: This paper presents the results of the analysis of 107 ecotourism trips to the Alto Ribeira State Tourist Park, aiming to verify the role of directed and intensified contact with nature in the process of Environmental Education. Meetings with Focal Groups were held a few days after arriving, as a way both to verify personal opinions about the trips and to do a quantitative and qualitative analysis of the trips, comparing them with similar activities carried out by other agents, but with a more informal character, which is a strong feature of the Ecotourism market. The analysis was based on the Collective Subject Speech (CSS) method. The results point out the substantial differences in the interviewers' perception, reinforcing the hypothesis that Ecotourism must promote a more intensive contact with nature to become an effective Environmental Education instrument.

Keywords: Ecotourism, Environmental Education, Environmental Perception.

1 Professor Adjunto da Universidade Federal de São Carlos / Laboratório de Ecoturismo, Percepção e Educação Ambiental (LEPEA), campus de Sorocaba. Contato: Rodovia João Leme dos Santos, SP-264 km 110 - Itinga, Sorocaba - SP. CEP: 18052-780. E-mail: zysman@ufscar.brou zysman@physis.org.br.

2 Professora Assistente da Universidade Federal de São Carlos, campus de Sorocaba. 


\section{Introdução}

Apesar de diversos autores terem publicado trabalhos sobre o tema (GOMES, 2003; KINKER, 2005; LEAL-FILHO, 2005; PIRES, 2002; RODRIGUES, 2003; SALVATI, 2003, entre outros), uma prática instrumental da Educação Ambiental (EA) que precisa ser mais bem estudada e compreendida é o Ecoturismo. Encontros sobre o tema evidenciam o grau de distorção sobre a sua prática, mas não há como pensar em outra que não envolva alguns pontos básicos: planejamento sustentável, EA e inclusão social, além de viagens com destino à natureza e que garantam o respeito à cultura local (BENI, 1999; CEBALLOSLASCURÁIN, 1995; HONEY, 1999; MITRAUD, 2003; NEIMAN; MENDONÇA, 2000; RUSCHMANN, 2000;).

No entanto, apesar de o Ecoturismo ser definido como um promissor campo de atuação para os educadores ambientais, a sua prática no Brasil ainda está longe de atingir esse objetivo. Além da falta de articulação e envolvimento com comunidades locais residentes em áreas onde são implantados projetos de Ecoturismo, nota-se uma preocupação crescente quanto aos aspectos relacionados com o "uso" da natureza como "mercadoria" e a conseqüente devastação ambiental. Muitos dos erros cometidos no modelo econômico vivido na sociedade - lucro, ganância, degradação - são repetidos no turismo, diminuindo sua credibilidade (CORIOLANO, 2002).

Bruhns (2000) defende que, apesar do discurso ecológico apresentado pelos profissionais que organizam atividades de esportes de aventura, realizados normalmente em cachoeiras, trilhas e montanhas, e da percepção que os praticantes adquirem de estar harmonizados e integrados à natureza, o que se verifica, de fato, é que o caráter inofensivo dessas práticas não se sustenta.

As divergências filosóficas, ideológicas e conceituais sobre o Ecoturismo talvez representem o tópico central a ser equacionado e trabalhado metodologicamente como ponto de partida para o desenho estratégico de programas efetivos de EA. Existem sérios equívocos no que tange às práticas, ao planejamento e às atitudes vivenciadas em atividades realizadas em áreas naturais. Urgem reflexões que apontem novas 
perspectivas para uma lógica pautada em possibilidades de superação do lazer "mercadológico" e mal planejado em direção a uma conscientização ambiental.

A maior dificuldade talvez advenha do fato de o Ecoturismo ser uma idéia "guarda-chuva", uma vez que diversas práticas, como caminhadas, escaladas, rapel, espeleologia, cavalgadas, mergulho, passeios de barco, vela, vôo livre, balonismo, estudos do meio, safári fotográfico, observação de fauna e de flora, turismo esotérico e turismo rural, são igualmente entendidas como vertentes dessa atividade (SERRANO, 2000). Dentro dessa enorme gama de possibilidades, a EA vem freqüentemente sendo relegada para segundo plano.

Neiman (2005) acredita que as agências de Ecoturismo possuem um caráter estritamente empresarial. Dessa forma, sem a atuação educadora de todos os profissionais envolvidos com o Ecoturismo, tornase mais difícil vislumbrar importantes processos de mudança de valores e atitudes. Por ter surgido como um negócio, o setor ecoturístico não se propôs, ainda, a refletir sobre o que faz. Produz viagens e não prioritariamente experiências, nem conhecimento. Só reproduz estratégias de marketing e conceitos administrativos convencionais, aplicados tradicionalmente a outras áreas do chamado mercado turístico (NEIMAN; MENDONÇA, 2000).

Para Jesus (2003), o poderoso circuito do marketing transformou aquilo que se propunha um modelo alternativo ao trade numa forma de turismo predatório que, mesmo embebido de um discurso ecológico, não discrimina ações pautadas na sustentabilidade daquelas experiências nas quais a natureza comparece unicamente como alvo e motivação da superação de limites aos aventureiros que a praticam.

No que se refere à sua ligação direta com a EA, algumas ponderações são necessárias. Basta colocar o indivíduo em contato com a natureza para estar educando-o? Ensinar "ecologia" numa trilha em um ambiente natural é fazer "Educação Ambiental"? Há durante as atividades de Ecoturismo uma relação automática entre os aspectos ambientais das áreas protegidas e as antropizadas e que será percebida após a viagem?

É no intuito de apresentar novos elementos que ajudem a responder a essas perguntas que se realizou este estudo, baseado na 
realização de viagens de Ecoturismo que promoveram contato dirigido e intenso com a natureza, realização de Grupos Focais após as viagens com alguns participantes e questionário para a construção de Discurso do Sujeito Coletivo.

\section{Método}

\subsection{Descrição das atividades desenvolvidas}

Entre 1991 e 2006, foram realizadas observações participantes em 107 viagens de Ecoturismo ao Parque Estadual Turístico do Alto Ribeira (PETAR), em Iporanga, SP, localizado no Vale do Rio Ribeira de Iguape, a $350 \mathrm{~km}$ da cidade de São Paulo. A região do PETAR é uma das últimas áreas de Mata Atlântica conservadas do Estado e é considerada o local com maior concentração de cavernas no Brasil, além de cachoeiras, rios, montanhas, vales, fauna e flora ameaçadas de extinção.

Por serem interpretados pelo visitante como ambientes "intocados", a Mata Atlântica e as cavernas do PETAR têm sido muito procuradas como destinos do Ecoturismo e freqüentam o imaginário dos cidadãos urbanos dos grandes centros emissores (Grande São Paulo, principalmente, e Curitiba). Esse aspecto simbólico é, inclusive, muito explorado pelo marketing praticado pelas agências de Ecoturismo que trabalham na região.

Após cada uma das viagens, nas quais participaram cerca de 3.000 pessoas, as atividades dirigidas de contato com a natureza foram discutidas por uma equipe de profissionais e os procedimentos foram refeitos para novas experimentações, até que se chegasse a uma estratégia de trabalho que, acredita-se, tem grande influência no desenvolvimento de comportamentos pró-ambiente dos participantes das viagens. Os pesquisadores, apesar de exercerem o papel de "guias" dos grupos, fizeram parte do mesmo, vivenciando com todos as mesmas experiências ao longo de dois ou três dias.

O objetivo educacional do trabalho realizado nessas viagens é adquirir uma melhor compreensão do valor da conservação da natureza e 
da diversidade sociocultural, priorizando a sensibilização do indivíduo quanto à importância do seu papel na construção de um mundo diferente, tanto na relação sociedade-natureza quanto na dos indivíduos entre si. $\mathrm{O}$ Ecoturismo é, portanto, entendido como ferramenta para a EA.

A aposta metodológica foi o potencial transformador das vivências das pessoas entre si e com o meio através do contato dirigido e intensificado com a natureza. Foram criadas estratégias que promoveram experiências pessoais e coletivas através da exposição a limites pessoais, medos, inseguranças e sucessos e da atuação em equipe (pressupondo confiança, solidariedade e afeto), cuidando-se para que as atividades não perdessem o caráter lúdico, normalmente associado ao Ecoturismo. Valorizou-se o olhar menos analítico e mais subjetivo sobre a realidade.

De modo a propiciar vivências com situações que envolvem medo, fascínio, insegurança e limitação com relação às obras da natureza, os participantes foram conduzidos por trilhas e cavernas onde ficaram expostos a "obstáculos" com os quais não estão acostumados em seu cotidiano. O próprio ambiente das cavernas se lhes apresenta como "estranho", "desconhecido" e até mesmo "inexpugnável". O mesmo vale dizer para a floresta, que para a maioria dos participantes das viagens também carrega uma grande quantidade de significados misteriosos e desafiadores.

Os guias foram orientados para ajudar, o mínimo possível, na superação das dificuldades individuais, proporcionando o surgimento do espírito cooperativo dos demais participantes, numa clara tentativa de estimular o exercício do altruísmo. Compartilhar a experiência pode funcionar como um amplificador do impacto da emoção da estada. A comunicação e a transferência de emoções sociais positivas com o ambiente natural podem contribuir para a emergência de uma maior afinidade emocional (KALS; SCHUMACHER; MONTADA, 1999). Por isso, nas caminhadas por trilhas e cavernas, estimulou-se ao máximo a cordialidade e solidariedade entre o grupo.

Enfim, o intuito das viagens foi não se limitar apenas a admirar as belas paisagens da mata e os cenários exóticos de dentro da caverna. A intenção foi gerar desconforto, não no sentido físico (que é inevitável), mas 
somente para provocar reflexões mais profundas sobre o modo de vida de cada um.

As viagens tiveram a duração de dois dias e neles, através de uma imersão no ambiente visitado, os participantes puderam conhecer pessoas e lugares novos e inusitados. Foram estimulados a perceber, a cada momento, todas as possibilidades de enriquecimento pessoal desse contato direto com culturas tão díspares. Na verdade, o que se objetivou foi a formação de um cidadão capaz de perceber que existem muitos modos de viver e que o seu não é obrigatoriamente o melhor, mas apenas mais um.

\subsection{Instrumentos de coleta de informações e análise de depoimentos}

Neste estudo, foram utilizados os dois instrumentos descritos a seguir:

a) Grupos Focais, com participantes de viagens opinando sobre aspectos relacionados ao contato com o meio natural:

Numa tentativa de compreender melhor os fenômenos comportamentais observados ao longo das viagens, foram realizadas reuniões com Grupos Focais alguns dias após o regresso, de modo a verificar as opiniões pessoais sobre as viagens e as impressões remanescentes, passado o "entusiasmo natural" verificado durante a participação das atividades em campo. O propósito dessa etapa era avaliar, qualitativamente, a retenção dos comportamentos e sentimentos trabalhados nas viagens.

O Grupo Focal é uma técnica de avaliação que oferece informações qualitativas e na qual o moderador guia grupos pequenos numa discussão que tem por objetivo revelar experiências, sentimentos, percepções, preferências (DIAS, 2000).

Foram realizados três Grupos Focais, todos seguindo os mesmos critérios. Para a seleção dos debatedores foram convidados, após sorteio aleatório, 10 participantes de viagens ao PETAR, entre os quais sempre havia dois representantes de cada viagem ( 5 viagens no total), de modo que a maioria não se conhecia previamente. A única exigência era que, para cada participante, a viagem tivesse acontecido há pelo menos 10 dias da 
realização do Grupo Focal. Dessa forma, 12 dias foi o prazo mínimo observado para dois participantes de cada Grupo e 64 dias para outros dois participantes de cada Grupo. Os demais (6 para cada Grupo) haviam viajado dentro desse intervalo.

Todos os participantes estavam vagamente informados sobre o tema da discussão, para que não comparecessem com idéias preestabelecidas, e aceitaram o convite de livre e espontânea vontade, sem receber qualquer espécie de gratificação. O moderador conduziu a discussão de forma que os participantes pudessem opinar livremente sobre suas impressões a respeito das viagens realizadas e as principais conseqüências que supostamente elas produziram na vida de cada um. Tomou, também, o cuidado de conduzir os tópicos e sua seqüência no debate para aspectos da questão que precisavam ser abrangidos, principalmente sobre o efeito das viagens na geração de percepções novas e/ou comportamentos derivados. Todos foram encorajados a opinar.

Ao final de cada reunião, foi efetuado um agradecimento à participação de cada um e solicitada sua permissão para que as discussões pudessem ser resumidamente relatadas neste artigo. A reunião com cada grupo teve a duração média de 90 minutos. Após cada reunião, foi elaborado um relatório com o resumo das informações e impressões obtidas, levando-se em consideração as palavras utilizadas repetidamente, o contexto no qual a informação foi obtida e as concordâncias entre as opiniões dos participantes.

b) Entrevistas com participantes (e não-participantes) de viagens para a construção de Discurso de Sujeito Coletivo:

O Discurso do Sujeito Coletivo (DSC) é uma reunião em um só discurso-síntese homogêneo de Expressões-Chave (pedaços, trechos ou segmentos do discurso, contínuos ou descontínuos, que revelam a essência do discurso ou a teoria subjacente), que têm a mesma Idéia Central (nome ou expressão lingüística que revela e descreve da maneira mais sintética e precisa possível o sentido e o tema das Expressões-Chave de cada um dos 
discursos analisados ou Ancoragens ${ }^{3}$ e de cada conjunto homogêneo de Expressões-Chave). As idéias Centrais (ICs) representam o que o entrevistado quis dizer (ou sobre o que) e as Expressões-Chave (ECHs), como isso foi dito. O DSC foi criado com um expediente que institui um discurso do social na "primeira pessoa" com o objetivo de estar mais próximo do pensamento de uma coletividade (LEFÈVRE, F.; LEFÈVRE, A. M.; TEIXEIRA, 2000).

Essa parte do estudo faz uma análise quantiqualitativa das viagens ao PETAR, comparando-as com atividades similares realizadas por outros agentes, mas com caráter mais informal, característica marcante do mercado de Ecoturismo. O método empregado procura responder à pergunta central deste trabalho: há diferenças entre um trabalho de condução dirigido e o não dirigido no que se refere a sua eficiência na formação de atitudes pró-ambiente?

De modo a investigar mais opiniões sobre as viagens e sua importância para as pessoas, foram aplicadas, via correio eletrônico, cerca de 500 pequenas entrevistas abertas dirigidas, das quais se obteve resposta de 83 participantes de viagens organizadas pelo pesquisador ao PETAR (Grupo 1) e de 85 participantes de viagens de Ecoturismo com outras agências do setor do Ecoturismo (Grupo 2). As questões sobre as quais os entrevistados poderiam opinar livremente (abaixo) foram elaboradas com o intuito de detectar opiniões gerais sobre a relação ser humano x natureza, não tendo, portanto, ligação direta com viagens realizadas. No entanto, como o questionário foi enviado para dois grupos bem distintos (participantes de viagens para o PETAR e participantes de viagens com outras agências), as respostas puderam evidenciar o papel que as mesmas tiveram na formação da opinião das pessoas. Para cada uma das questões abaixo (a partir da de número 5), foi elaborado o Discurso do Sujeito Coletivo.

3 Ancoragem é a expressão de uma dada teoria, ideologia, crença religiosa que o autor do discurso professa e que está embutida no seu discurso como se fosse uma afirmação qualquer. 


\section{Questionário enviado por correio eletrônico}

1) Nome

2) Idade

3) Escolaridade

4) Instituição de Ensino

5) Caso tenha tido oportunidades, descreva quais as principais situações em que você pôde ter contato com a natureza.

6) Relate suas impressões sobre essas experiências.

7) Nos dias atuais, muitos indivíduos se consideram "educados ambientalmente". O que você pensa a esse respeito?

8) A trajetória de vida das pessoas pode apresentar episódios que influenciam ou até mesmo determinam a forma como elas se relacionam com o meio ambiente, positiva ou negativamente. No seu caso, relate brevemente como esses episódios se deram.

9) Como você classificaria a sua relação pessoal com a questão ambiental?

10) Você considera a Preservação da Natureza uma questão importante, independentemente da sua relação com a questão ambiental? Por quê?

\section{Análise e discussão dos resultados}

\subsection{Grupos Focais}

Durante as discussões, houve temas com grande concordância de opiniões entre os participantes. Para a quase totalidade, a viagem ao PETAR tinha sido uma experiência muito diferente, algo que jamais tiveram, mesmo se considerando outras viagens similares realizadas por alguns. Quando questionados sobre qual seria esse diferencial, a maioria aponta o trabalho dos guias e algumas características das atividades realizadas como fundamentais para essa percepção, como o contato com a "natureza selvagem" e a emoção de "vencer os desafios" das cavernas. A 
escuridão e as possibilidades de reflexão sobre aspectos da vida e dos sentimentos de cada um também foram mencionados.

O sentimento de amizade e companheirismo foi outro aspecto destacado como um dos mais significativos que experimentaram e trabalharam. Houve muitos depoimentos de participantes que alegaram ter feito grandes amizades na viagem e que conversar sobre ela com esses amigos era fato corriqueiro desde então.

Alguns poucos manifestaram não ter havido grandes mudanças, alegando como motivo o fato de que o PETAR, por ser um ambiente muito diferente daqueles nos quais a humanidade vive, não serviria como um bom referencial de comparação. A maioria, no entanto, discordou dessa posição e apontou os atrativos do PETAR como ótimos exemplos daquilo que a humanidade perdeu, em termos de vivência, quando optou pelo urbano. Todos, apesar dessa divergência de alguns, manifestaram enorme desejo de regressar ao PETAR e se declarariam defensores do Parque caso soubessem que sua participação seria necessária perante alguma ameaça futura à integridade do mesmo.

A grande maioria aponta a viagem ao PETAR como sua experiência de contato com a natureza mais marcante e acredita que essa lembrança será levada para a vida inteira. Foram freqüentes as manifestações de que a viagem permitiu um descanso da rotina estressante do ambiente urbano e um despertar para a beleza da natureza. O fascínio em descobrir um mundo desconhecido, as emoções advindas dessa descoberta, os sentimentos controversos simultaneamente experimentados e o autoconhecimento proporcionado pela viagem foram temas longamente discutidos.

Apresentaram sugestões para a melhoria da organização das atividades, mas solicitaram que a essência da viagem (seu roteiro, equipe, objetivos e estrutura) fosse mantida, pois estava nela a diferença em relação a outras experiências que tiveram.

Quando questionados se a viagem tinha colaborado para a sua "transformação" em defensores da causa ambiental, foram unânimes em dizer que sim, apesar de alguns declararem que já manifestavam esse desejo anteriormente. Para esses, a viagem só fez aflorar uma vontade latente, que ficou evidenciada com a experiência no PETAR. 
Notam-se, em cada pequeno depoimento dos Grupos Focais, alguns elementos importantes. Mesmo se passando pelo menos 10 dias entre as experiências da viagem e as entrevistas, o tom e a ênfase com que cada participante defende seu ponto de vista dá a impressão de que os depoimentos foram recolhidos no "calor" da atividade em si. E o mesmo vale dizer, embora esta percepção não esteja sistematizada, para participantes de viagens que ocorreram muitos anos antes. É comum encontrarmos pessoas que foram ao PETAR há mais de dez anos e ainda comentam: "Puxa, aquela viagem... Você não sabe como foi importante para mim..." ou 'Nunca mais esqueci aquelas cavernas?'.

$\mathrm{O}$ que marcou tanto essas pessoas? $\mathrm{O}$ que mudou na sua percepção sobre o ambiente, nos seus valores? Parece-nos que não é temerário afirmar que o contato com a natureza, do modo intenso como foi proporcionado pelas viagens ao PETAR, tenha importante papel nesse processo. Trata-se de um fenômeno que escapa ao senso comum do "amo a natureza", decorrente da valorização cultural das questões ambientais que conhecemos no mundo contemporâneo. Afinal, para outras tantas experiências de contato que não foram tão dirigidas e valorizaram com ênfase menor as vivências sensoriais e emocionais, as marcas podem se mostrar menos duradouras. Intensificar a experiência através dos sentimentos parece ser estratégia eficaz para o afloramento do sentido de pertencimento ao mundo natural.

\subsection{Discurso do Sujeito Coletivo}

Vejamos agora as respostas ao questionário aplicado via correio eletrônico e a construção dos DSCs:

3.2.1. Questão 5 - Caso tenha tido oportunidades, descreva quais as principais situações em que você pode ter contato com a natureza.

No caso do Grupo 1, obtiveram-se 72 respostas para essa questão, das quais $92,28 \%$ mencionaram as viagens como principais acontecimentos que permitiram vivenciar o contato com a natureza. Quanto aos tipos de viagem, tem-se a seguinte distribuição de respostas: "busca despretensiosa por contato com a natureza" (19), "visitas técnicas de instituições de 
ensino" (11), "estudos" (11), "trabalho" (11), "esportes de aventura" (8) e "viagem rotineiramente realizada" (sítios, casas de praia etc.) (7).

Entre os destinos citados, o PETAR aparece mais vezes (27). Outros 40 destinos, todos no interior do estado de São Paulo, foram citados (Tatuí, Campos do Jordão, Brotas, Parque Estadual de Carlos Botelho, Cotia, Monteiro Lobato, Bocaina, Lindóia, entre outros). Houve ainda 16 citações do litoral paulista (Ilha do Cardoso, Ilha Bela, Bertioga, Ubatuba, entre outros), 28 de outros estados do Brasil, 7 de parques urbanos e 4 de localidades no exterior. Os discursos do sujeito coletivo do Grupo 1 que puderam ser construídos para essa questão são:

DSC1 - Grupo 1 - "As principais situações em que tive contato com a natureza foram quando fui viajar para..."

DSC2 - Grupo 1 - "Na minha vida em geral, desde pequeno, sempre tive contato com a natureza, especialmente nas férias e finais de semana ou morando no interior e freqüentando sitios ou fazendas de parentes, de modo que cresci em contato com a natureza. Nessas ocasiões, geralmente faço caminhada na mata ou pratico algum esporte de aventura".

No caso do Grupo 2, para a questão 5 obtiveram-se 77 respostas, das quais $90,9 \%$ mencionaram as viagens como principais acontecimentos que permitiram vivenciar o contato com a natureza. Quanto aos tipos de viagem, temos a seguinte distribuição de respostas: "busca despretensiosa por contato com a natureza" (27), "visitas técnicas de instituições de ensino" (6), "estudos" (6), "trabalho" (4), "esportes de aventura" (19) e "viagem rotineiramente realizada" (sítios, casas de praia etc.) (8).

Entre os destinos citados, Brotas - SP aparece mais vezes (26). Outros 37 destinos, todos no interior Estado de São Paulo, foram citados (Campos do Jordão, PETAR, Parque Estadual de Carlos Botelho, Gonçalves, Cotia, Monteiro Lobato, Bocaina, Lindóia, entre outros). Houve ainda 19 citações do litoral paulista (Ilha do Cardoso, Ilha Bela, Bertioga, Ubatuba, entre outros), 32 de outros estados do Brasil, 2 de parques urbanos e 6 de localidades no exterior. Os discursos do sujeito coletivo do Grupo 2 que puderam ser construídos para essa questão são: 
DSC1 - Grupo 2 - "Sempre que possivel, procuro viajar para ter contato com a natureza...".

DSC2 - Grupo 2 - "Na minha vida em geral, desde pequeno, sempre tive contato com a natureza, especialmente nas férias e finais de semana ou morando no interior e freqüentando sitios ou fazendas de parentes, de modo que cresci em contato com a natureza. Nessas ocasiões, geralmente faço caminhada na mata ou pratico algum esporte de aventura".

Nota-se que para a quase totalidade dos entrevistados as viagens parecem ser as principais oportunidades de contato com a natureza, uma vez que uma pequena minoria ( 7 no Grupo 1 e 2 no Grupo 2) identificou essa possibilidade em parques urbanos.

O conceito de natureza já não pertence ao território do citadino, sendo-lhe atribuída outra territorialidade, projetada para lugares distantes. O indivíduo não se sente "na natureza", ele precisa "ir à natureza", o que talvez revele um dos motivos para o sucesso das atividades de Ecoturismo nos tempos atuais. Quando muito, alguns apontam o contato com a natureza quando moravam no campo, na infância ou quando ali vão passar as férias, como revela um dos discursos do sujeito coletivo construído para essa questão 5, idêntico para ambos os Grupos.

\subsubsection{Questão 6 - Relate suas impressões sobre essas experiências.}

Para a questão 6 obtiveram-se 83 respostas do Grupo 1, que podem ser agrupadas em 4 categorias básicas, de acordo com o que os indivíduos alegaram sentir: harmonia/calma/equilíbrio (30), felicidade/bem-estar/prazer (20), preocupação com a conservação e indignação com a situação atual (18) e superação/recarga de energias (15).

Para essa questão 6, o discurso do sujeito coletivo do Grupo 1 é:

DSC - Grupo 1 - "Penso que esses contatos são essenciais e proporcionam qualidade de vida, são sempre algo renovador, em que você recarrega a 'bateria', além de serem sempre momentos inesqueciveis e de muita paz. Um grande sentimento de integração e em harmonia com a natureza, onde me sinto vivo. Buscando lugares tranqüilos, obtém-se calma, harmonia e equilíbrio necessários para o nosso dia-a-dia. Quando estou em um lugar bonito em contato com a 
natureza, procuro registrar o momento, como se fosse uma foto com brisa e sons. Guardo os momentos na memória e muitas vezes no meio do estresse do dia-a-dia procuro resgatá-los, numa tentativa de reequilibrar-me".

Salientam-se, nesse discurso, os sentimentos de prazer pelo contato com a natureza, quer sejam eles retrato do imaginário construído socialmente, quer de fato proporcionem bem-estar físico e psicológico.

Ainda para essa questão 6 obtiveram-se 85 respostas do Grupo 2, que podem ser agrupadas nas mesmas 4 categorias básicas, de acordo com o que os indivíduos alegaram sentir: "harmonia/calma/equilíbrio" (22), "felicidade/bem-estar/prazer" (18), "preocupação com a conservação e indignação com a situação atual" (15) e "superação/recarga de energias" (30).

Para essa questão 6 o discurso do sujeito coletivo do Grupo 2 é:

DSC - Grupo 2 - 'Penso que esses contatos são importantes para os sentimentos de superação dos limites pessoais e ampliação de nossa visão de mundo e da natureza, de que somos capazes de vencer. Voltamos sempre com uma nova energia que nos impulsiona para a vida cotidiana e nos garante um equilíbrio pessoal. Lugares bonitos ajudam a aliviar o estresse e a obter calma, harmonia e equilíbrio, necessários para o nosso dia-a-dia".

Nesse grupo, apesar de também transparecerem os mesmos sentimentos, há uma predominância de "energia/renovação" que parece coincidir com o aumento na freqüência dos praticantes de esportes de aventura. Há, por parte de praticantes e profissionais, uma confusão de terminologias e percepções sobre as diferenças entre o chamado Ecoturismo e o Turismo de Aventura, e a forma como é direcionada a experiência de contato parece ser fundamental na determinação das impressões que permanecem. Do nosso ponto de vista, o chamado Turismo de Aventura tem apostado menos nas vivências com o meio natural de caráter mais contemplativo (típicas do Ecoturismo) e mais na "superação de limites", na sobreposição de obstáculos, uma visão que reforça a imagem de uma natureza "oponente" que pode ser "vencida". Essa característica costuma promover nos praticantes sentimentos mais 
egocêntricos do que na sua relação e equilíbrio com o meio. Apesar de os estudos de Bruhns (1997), Marinho (1999) e Schwartz e Silva (1999) ressaltarem o papel da natureza como possibilidade de ser percebida como parceira, essa não tem sido a prática das atividades de Turismo de Aventura observadas no mercado.

Mesmo tendo em comum com o Ecoturismo o contato com o ambiente natural, o direcionamento da percepção pode diferir radicalmente no caso do Turismo de Aventura, inclusive comprometendo o respeito ao seu princípio básico de conservação. Para Schwartz (2002), no entanto, a busca pelo prazer, pela emoção e pela aventura pode promover alterações de atitudes e valores capazes de interferir na perspectiva de mudanças de estilos almejada no mundo contemporâneo, pois oferece a possibilidade de vivenciar sentimentos de prazer e ampliação do senso de limite da liberdade e da própria vida. Assim, devido a essas características similares entre as duas práticas, os membros do Grupo 2 apontam com freqüência ainda significativa os sentimentos de "harmonia/calma/equilíbrio", fato que reforça o vigor do contato com a natureza como agente transformador.

Para Bruhns:

Esses esportes, através da experiência sensível por eles provocada, e fundamentados numa ética de respeito e não de dominação, acabam por demonstrar uma forma de conhecimento interligado a determinadas emoções, fundidas com os sentidos corporais, no contato com a natureza. Uma experiência de contemplação, filtrada por valores e concepções de vida[,] pode emergir, bem como um sentimento de união pelo pertencimento a um cosmo comum e uma fusão, através das "relações de composição" (BRUHNS, 2000, p. 44-45).

\subsubsection{Questão 7 - Nos dias atuais, muitos indivíduos se consideram "educados} ambientalmente". O que você pensa a esse respeito?

A intenção dessa questão era recolher opiniões dos entrevistados sobre sua concepção de eficiência do processo que convencionamos chamar de construção social para a obtenção de Educação Ambiental, ou seja, o quanto o tema, de grande apelo midiático, está realmente sendo 
eficiente na mudança de atitudes e/ou na geração de uma consciência ambiental efetiva.

Obtiveram-se 82 respostas do Grupo 1 e 85 respostas do Grupo 2, e 81,7\% do Grupo 1 (67 pessoas) e 75,29\% (64 pessoas) não concordam que existam indivíduos "educados ambientalmente". Alguns, fazendo uma auto-avaliação, se julgam no caminho de estarem ambientalmente educados, mas ainda não estão. Pela semelhança das respostas entre os Grupos, elaborou-se um único discurso do sujeito coletivo para essa questão 7:

DSC - Grupos 1 e 2 - "Embora a conscientização tenha aumentado, nos dias atuais não se pode dizer que existam indivíduos ambientalmente educados, pois ser educado é muito mais do que não jogar papel na rua ou economizar água. A Educação Ambiental começa em casa, em atitudes individuais e exemplos do dia-a-dia, e não como discurso ou prática apenas quando se está "na mata". É só olhar ao redor, na cidade em que vivemos, para ver como nos relacionamos com o meio ambiente. A maioria não possui o minimo de educação. O discurso é sempre fácil, mas a prática é outra. É um processo contínuo que foi iniciado, mas todos temos muito que aprender ainda".

$\mathrm{Na}$ opinião dos entrevistados de ambos os Grupos, a EA, com suas mais diversas estratégias, ainda não foi suficientemente eficaz na transformação de valores dos indivíduos, sendo a atitude "ecologicamente correta" muito mais retórica que real.

Quais seriam, então, as motivações pessoais para o envolvimento (ou não) dos indivíduos com a questão ambiental? A questão seguinte busca a resposta.

3.2.4. Questão 8-A trajetória de vida das pessoas pode apresentar episódios que influenciam ou até mesmo determinam a forma como elas se relacionam com o meio ambiente, positiva ou negativamente. No seu caso, relate brevemente como esses episódios se deram.

Inicialmente, serão analisadas as respostas do Grupo 1. Para essa questão obtiveram-se 83 respostas, em que se observa que os entrevistados identificam 5 categorias principais de opinião, as quais foram consideradas 
na elaboração do discurso do sujeito coletivo. 35 entrevistados consideram decisivo o contato que tiveram com a natureza em algum momento de suas vidas; 16 consideram as influências dos pais e demais familiares (avós e tios) como decisivas para o seu relacionamento com a natureza; 7 passaram a se relacionar e se preocupar com a natureza a partir de seus estudos acadêmicos; 4 atribuíram a seus contatos com outras culturas o respeito pela natureza (segundo eles, em outros países - Israel, Alemanha e Canadá - há uma preocupação ampla com a questão ambiental que inexiste no Brasil); e os demais (21) creditam a sua preocupação com a conservação ao exemplo de outras pessoas e ativistas.

O discurso do sujeito coletivo do Grupo 1 para essa questão é:

DSC - Grupo 1 - "Sempre tive contato com a natureza, desde pequeno. Isso influenciou muito minha história. Nela, graças ao trabalho de alguns profissionais e pessoas que conbeci, tive momentos de comoção e socialização em um meio natural, ao lado de cachoeiras, animais e isso remete a fatos positivos da minha vida, o que faz. com que, cada vez mais, eu procure por esses momentos. Acredito que a forma como meus pais e familiares me educaram também me influenciou a ter respeito pela natureza".

Aparecem nesse discurso dois elementos que podem ser centrais na formação dos comportamentos pró-ambiente: o exemplo de outras pessoas (pais, familiares, professores, ambientalistas, guias de Ecoturismo etc.) e o contato direto com a natureza.

Para a análise das respostas do Grupo 2 à questão 8, obtiveram-se 85 respostas, das quais se conclui que as experiências de contato com a natureza não parecem ser tão marcantes quanto no Grupo anterior, e apenas 4 categorias citadas com mais freqüência foram consideradas na elaboração do discurso do sujeito coletivo. 27 entrevistados consideram decisivo o contato que tiveram com a natureza em algum momento de suas vidas; 23 entrevistados consideram as influências dos pais e demais familiares (avós e tios) como decisivas para o seu relacionamento com a natureza; 24 atribuíram a seus contatos com outras culturas o respeito pela natureza; e apenas 11 creditam ao contato com outras pessoas e ativistas a sua preocupação com a conservação. 
O discurso do sujeito coletivo do Grupo 2 para essa questão é:

DSC - Grupo 2 - "Sempre tive contato com a natureza, desde pequeno, inclusive com culturas muito diferentes da minha através de viagens que realizei. Sem dúvida a influência de meus pais me ajudou a gostar da natureza. Eles me colocaram em contato com ela desde criança, me educando para respeitar".

Nesse discurso, os dois elementos que surgiram no Grupo 1 ganham força diferenciada. Parecem ser centrais na formação dos comportamentos pró-ambiente: 1) o exemplo de pais e outras pessoas da família e a influência de outras culturas e 2) o contato direto com a natureza. Nota-se a grande queda na freqüência da categoria "exemplo de pessoas e ativistas", o que parece revelar que os profissionais de Ecoturismo (que deveriam estar trabalhando a Educação Ambiental) não tiveram um papel tão significativo de transformação quanto no Grupo anterior. Tal fato revela a importância do trabalho orientado realizado no Grupo 1 e que foi, no mínimo, menos explícito no Grupo 2.

\subsubsection{Questão 9 - Como você classificaria a sua relação pessoal com a questão ambiental?}

Para a questão 9 obtiveram-se 83 respostas do Grupo 1 e 84 do Grupo 2, as quais, por mostrarem uma similaridade muito grande, sem discrepâncias relevantes, foram analisadas conjuntamente. 56 entrevistados afirmam estar fazendo a sua parte no que diz respeito à conservação ambiental; 34 afirmam se preocupar com a natureza e ser simpatizantes da causa ambiental; 31 dizem que a sua relação com a natureza é forte, boa e próxima; 24 afirmam estar estudando o assunto e de modo crescente construindo relação mais próxima com a natureza e com a questão ambiental; 22 afirmam ser passivos, fazer menos do que deveriam em prol da natureza; 20 afirmaram que ter atitudes de educar, conscientizar e sensibilizar as pessoas para a questão ambiental é o que podem fazer pela conservação da natureza; 8 afirmaram ter respeito pela natureza; 6 afirmaram que seu envolvimento se dá via trabalho, estudos ou projetos na área; e 4 afirmam estar revoltados e incomodados com a situação atual da conservação. 
O discurso do sujeito coletivo dos Grupos 1 e 2 para essa questão é:

DSC - Grupos 1 e 2 - "Faço a minha parte, mas sei que poderia ser mais ativo nessa questão, tento conscientizar as pessoas que estão ao meu lado, mas acho que minha relação poderia ser melhorada. Estou buscando informações para melhorar e ampliar minha atuação. Tento lutar pela causa ambiental, participar de protestos, fazer minha parte, me considero engajado com a questão ambiental, mas acho que poderia me esforçar mais e me dedicar mais do que me dedico atualmente".

Nota-se que apenas uma minoria $(11 \%)$ se declara passiva diante da questão ambiental, o que revela o apelo que o tema tem na sociedade nos tempos atuais. Essa relevância da temática também justifica os resultados observados na questão seguinte:

3.2.6. Questão 10 - Você considera a Preservação da Natureza uma questão importante, independentemente da sua relação com a questão ambiental? Por quê?

Para essa questão, das 84 respostas obtidas no Grupo 1, 19 apontam a conservação atrelada às necessidades de recursos para a espécie humana, 39 ressaltaram o fato de sermos elos integrantes da natureza e 20 destacaram que a natureza tem direito à existência, independentemente das necessidades humanas.

O discurso do sujeito coletivo do Grupo 1 para essa questão é:

DSC - Grupo 1 - "Claro que considero a preservação da natureza importante, pois fazemos parte dela, somos mais um de seus elos, e isso nos proporciona grande prazer, tanto pelo possivel contato direto quanto pelo simples fato de saber que ela está lá e bem. Mesmo que o ser bumano a agrida constantemente, a natureza tem o direito de continuar a existir. Destrui-la significará comprometer nossa própria qualidade de vida e implicará a falta de recursos para sobrevivermos".

A visão conservacionista utilitária $(23 \%)$ é aqui minoritária em relação aos motivos menos antropocêntricos, que somados atingem 71\%. Esse grupo revela um respeito verdadeiro ao meio natural, uma afeição e um altruísmo que não se verificam no Grupo 2, como será visto em 
seguida. O trabalho de sensibilização pareceu ter sido mais eficiente para esse Grupo, o que revela a influência do contato dirigido e a mudança de valores dele decorrente.

O Grupo 2 apresenta uma visão bem diferenciada para a questão 10: obtiveram-se 83 respostas, das quais 59 atribuem a necessidade de conservação às necessidades da espécie humana, já que dependemos da natureza para existirmos, 10 ressaltaram o fato de fazermos parte da natureza e 10 destacaram que a natureza tem direito à existência, independentemente das necessidades humanas.

O discurso do sujeito coletivo do Grupo 2 para essa questão é:

DSC - Grupo 2 - "Claro que considero a preservação da natureza importante. Acho fundamental que as pessoas saibam o quanto a natureza é importante para a nossa sobrevivencia e o quanto é bom interagir com ela. Dela depende o futuro do planeta. Preservar a natureza é preservar a si mesmo, nosso futuro está em jogo, a qualidade de nossa vida está em questão. Quando falamos em preservação da natureza, estamos falando da preservação de nossa própria espécie, pois o ritmo atual de desenvolvimento não poderá ser sustentado por longo tempo. Isso sem falar na questão ética do direito à vida das outras espécies”.

A visão conservacionista utilitária é a preponderante (71\%), o que revela que para esse grupo, mesmo com o crescimento do debate sobre os impactos do modelo civilizatório, os paradigmas não são substituídos, mas apenas ajustados a uma lógica que acredita ser possível a continuidade do desenvolvimento da sociedade de consumo com a preservação dos recursos naturais. A racionalidade capitalista/utilitarista, que enxerga a natureza como "recurso", impõe a sua força, e o discurso reflete um conservacionismo atrelado à retórica do desenvolvimento sustentável.

\section{Conclusão}

Apesar da pequena quantidade de estudos empíricos que forneçam fundamentação para programas similares, Bolscho, Eulefeld, Rost e Seybold (1990) apontam que é possível promover o comportamento pró- 
ambiente através de experiências diretas com a natureza que utilizem todos os sentidos.

A percepção da paisagem é derivada de fatores educacionais e culturais e de fatores emotivos, afetivos e sensitivos, sendo estes últimos oriundos das relações que o observador mantém com o ambiente. A interpretação da paisagem está sob controle direto da maneira como cada um enxerga o mundo a partir de sua história pessoal, experiências prévias e expectativas, mas a experiência vivida pode ajudar a construir um novo conhecimento (FERREIRA; COUTINHO, 2000).

Guimelli (1994) defende que um grupo só vai sentir a necessidade de "reconstruir" a representação que forjou sobre determinado objeto quando perceber que, se não o fizer, perderá o "controle" da situação, possibilitando o surgimento de novos eventos suscetíveis de ameaçar sua organização atual e colocando em risco a identidade e a coesão entre seus membros. Nesse caso, forçado pelas circunstâncias, o grupo vai, progressivamente, "adaptando" novas práticas às anteriores, o que não significa que o núcleo de sua representação sobre o referido objeto seja, necessariamente, transformado. Isso vai depender do grau de contradição que essas novas práticas tenham em relação às práticas antigas do indivíduo e/ou do grupo, bem como da forma como as mudanças ocorridas são percebidas pelos sujeitos. Assim sendo, é na desestruturação dos conceitos de "domínio sobre a natureza", ou seja, nos sentimentos contraditórios e simultâneos que os indivíduos experimentam (medo e fascínio) quando se percebem à mercê da mesma, que se abre a brecha para a mudança das representações e dos valores individuais acerca da sua relação com ela. Em outros termos, quando os sujeitos entendem que as mudanças provocadas em seu ambiente "natural", em função de novas práticas, são irreversíveis, o processo de transformação das representações parece fatal. Por outro lado, quando os sujeitos entendem que são mudanças passageiras, ou seja, que é possível retornar às práticas antigas, após certo período, as representações são modificadas apenas superficialmente (GUIMELLI, 1994).

A educação, a percepção e o lúdico devem ser utilizados para possibilitar a expansão de uma consciência conservacionista através, sempre, do envolvimento afetivo das pessoas com a natureza e as culturas 
locais, numa tentativa de apropriação desse novo território como seu. A transformação de espaços em lugares, como propõe Tuan (1983), foi estimulada no PETAR devido tanto aos atrativos facilitadores que auxiliam essa transformação quanto à forma como as atividades foram conduzidas.

Quanto maiores são as diferenças existentes entre o ambiente visitado e o do cotidiano do indivíduo, maiores são os contrastes encontrados e, portanto, mais instigantes os questionamentos. A retirada do cotidiano propicia ao cidadão a possibilidade de, no contato direto com novas realidades, repensar o seu próprio modo de vida, analisando a sua qualidade e reelaborando seus valores e conceitos.

Quando estão em contato com a Natureza, os muitos caminhantes enfrentam diferentes níveis de dificuldade, surpreendem-se com diversos fenômenos, compartilham sentimentos semelhantes. Confirmam sua própria existência pela percepção simultânea e comunicação com o outro. Os sentimentos de complementaridade, as posturas de solidariedade costumam brotar espontaneamente nessas excursões. Há um enorme prazer em poder auxiliar o outro, expressar o que sabe e o que sente, dar a mão para ajudar a subir ou a descer, compartilhar as emoções, reconhecer a alegria de estar junto àquela companhia (MENDONÇA; NEIMAN, 2003).

Defende-se aqui que o apelo sensitivo e emocional de uma viagem deve ser o mais intenso possível, pois provocará, no indivíduo, a percepção do quanto ele perdeu em termos de experiências pessoais ao se encontrar afastado da natureza. Isso abalará sua convicção sobre a "naturalidade" do mundo culturalmente transformado no qual ele vive e sobre o quanto ele não o faz plenamente feliz. Está aí a chave para a verdadeira (re)Educação Ambiental. O sujeito deve ter claro que práticas cotidianas de sua vida já não são suficientes para lhe garantir o mesmo prazer que sentiu na viagem, no contato com a natureza. Novas percepções, novos valores reelaboram as representações sociais que temos, mas, para que isso ocorra, elas têm que ter forte significado pessoal. Não é através da superficialidade das experiências que vamos mudar hábitos extremamente arraigados em nossa sociedade tecnológica. Temos que ir ao íntimo do subconsciente humano para encontrar lá nossos verdadeiros anseios e ocultos sentimentos de ligação aos elementos naturais. 
Ao longo desses 16 anos, foi ficando cada vez mais evidente que a substituição das atividades centradas no raciocínio e na compreensão conceitual dos aspectos ambientais por outras que estimularam as sensações e emoções atingiu mais eficazmente os objetivos de sensibilização e tornou os depoimentos mais coerentes, previsíveis e apaixonados. A sinceridade com que os comportamentos pró-ambiente foram aflorando, tanto durante como após as viagens, reflete a força que o contato intensificado com o meio natural possui para eliciar os participantes. Estes gostam mais do lugar visitado à medida que o seu contato "físico" e "psicológico" com ele se torna mais intenso? As representações sociais (culturais) de valoração da natureza ficam mais evidentes quanto mais próximos estamos das sensações que ela nos provoca? A observação sistemática das transformações pelas quais passam os participantes dessas experiências nos faz acreditar em respostas positivas para cada uma dessas questões.

\section{Referências}

BENI, Mário Carlos. Análise estrutural do turismo. 3. ed. São Paulo: SENAC, 1999.

BOLSCHO, Dietmar; EULEFELD, Guenter; ROST, Juergen; SEYBOLD, Hansjoerg. Environmental education in practice in the Federal Republic of Germany: An empirical study. International Journal of Science Education, v. 12, p. 133-146, 1990.

BRUHNS, Heloísa Turini. Esporte e natureza: o aprendizado da experimentação. In: SERRANO, Célia Maria de Toledo (Org.). A educação pelas pedras: Ecoturismo e Educação Ambiental. São Paulo: Chronos, 2000. p. 25-46.

Lazer e Meio Ambiente: corpos buscando o verde e a aventura. Revista Brasileira de Ciências do Esporte, Ijuí, v. 18, n. 2, p. 86-92, 1997.

CEBALLOS-LASCURÁIN, Héctor. O ecoturismo como um fenômeno mundial. In: LINDBERG, Kreg; HAWKINS, Donald E. Ecoturismo: um guia para planejamento e gestão. São Paulo: SENAC, 1995. p. 23-29.

CORIOLANO, Luzia Neide Menezes Teixeira. O Ecoturismo e os hóspedes da natureza. In: BARRETO, Margarita; TAMANINI, Elizabete (Org.). Redescobrindo a ecologia no turismo. Caxias do Sul: EDUCS, 2002.

DIAS, Cláudia Augusta. Grupo focal: técnica de coleta de dados em pesquisas qualitativas. Informação e sociedade, João Pessoa, v. 10, n. 2, p. 141-158, 2000. 
FERREIRA, Luiz Fernando; COUTINHO, Maria do Carmo Barea. Educação ambiental em estudos do Meio: a experiência da Bioma Educação Ambiental. In: SERRANO, Célia Maria de Toledo (Org.). A educação pelas pedras: Ecoturismo e Educação Ambiental. São Paulo: Chronos, 2000.

GOMES, Patrício Melo. Ecoturismo: uma releitura dos Discursos. Brasília: IBAMA, 2003.

GUIMELLI, Christian. Transformation des représentations sociales, pratiques nouvelles et schèmes cognitifs de base. In: Structures et transformations des représentations sociales. Lausanne: Delachaux et Niestlé, 1994. p. 171-198.

HONEY, Martha. Ecotourism and Sustainable Development: Who Owns Paradise? Washington DC: Island Press, 1999.

JESUS, Gilmar Mascarenhas de. A leviana territoriedade dos esportes de aventura: um desafio à gestão do Ecoturismo. In: MARINHO, Alcyane; BRUHNS, Heloísa Turini. Turismo, Lazere e Natureza. Barueri: Manole, 2003.

KALS, Elisabeth; SCHUMACHER, Daniel; MONTADA, Leo. Emotional Affinity toward Nature as a Motivational Basis to Protect Nature. Environment and Behavior, v. 31, n. 2, p. 178-202, 1999.

KINKER, Sônia. Ecoturismo e conservaşão da natureza em Parques Nacionais. 2. ed. Campinas: Papirus, 2005.

LEAL-FILHO, Walter. A Educação Ambiental Aplicada ao Turismo: experiências da Costa de Caparica, Portugal. In: PEDRINI, Alexandre de Gusmão (Org.). Ecoturismo e Educação Ambiental. Rio de Janeiro: Publit, 2005. p. 23-29.

LEFÈVRE, Fernando; LEFÈVRE, Ana Maria Cavalcanti; TEIXEIRA, Jorge Juarez Vieira. O Discurso do Sujeito Coletivo: Uma nova abordagem metodológica em pesquisa qualitativa. Caxias do Sul: EDUCS, 2000.

MARINHO, Alcyane. Do Bambi ao Rambo ou vice-versa? As relações humanas com a (e na) natureza. Conexões: Educação, esporte e laz̧er - Faculdade de Educação Física da Unicamp, Campinas, n. 3, p. 33-41, dez. 1999.

MENDONÇA, Rita; NEIMAN, Zysman. À sombra das árvores: transdisciplinaridade e educação ambiental em atividades extraclasse. São Paulo: Chronos, 2003.

MITRAUD, Sylvia (Org.). Manual de Ecoturismo de base comunitária: ferramentas para um planejamento responsável. Brasília: WWF Brasil, 2003.

NEIMAN, Zysman. Natureza e cultura brasileiras: matérias-primas do Ecoturismo. In: NEIMAN, Zysman; MENDONÇA, Rita. (Org.). Ecoturismo no Brasil. Barueri: Manole, 2005. p. $17-40$.

NEIMAN, Zysman; MENDONÇA, Rita. Ecoturismo: discurso, desejo e realidade. Turismo em Análise, São Paulo, v. 11, n. 2, p. 98-110, nov. 2000.

PIRES, Paulo dos Santos. Dimensões do Ecoturismo. São Paulo: SENAC, 2002. v. 1. 272 p.

RODRIGUES, Adyr Balastreri. Ecoturismo: limites do eco e ética. In: Ecoturismo no Brasil: possibilidades e limites. São Paulo: Contexto, 2003. p. 29-46. (Org.).

RUSCHMANN, Dóris Van de Meene. A experiência do turismo ecológico no Brasil: um novo nicho de mercado ou um esforço para atingir a sustentabilidade. Turismo - Visão $e$ Ação, Itajaí, ano 2, n. 5, p. 81-90, out. 1999 / mar. 2000. 
SALVATI, Sérgio Salazar. Interpretação Ambiental. In: MITRAUD, Sylvia (Org.). Manual de Ecoturismo de Base Comunitária: ferramentas para um planejamento responsável. Brasília: WWF, 2003.

SERRANO, Célia Maria de Toledo. A educação pelas pedras: uma introdução. In:

(Org.). A educação pelas pedras: ecoturismo e educação ambiental. São Paulo: Chronos, 2000. p. 7-24.

SCHWARTZ, Gisele Maria. Emoção, aventura e risco - a dinâmica metafórica dos novos estilos. In: BURGOS, Miria Suzana; PINTO, Leila Mirtes Santos de Magalhães. Lazere e estilo de vida. Santa Cruz do Sul, RS: EDUNISC, 2002. p. 139-168.

SCHWARTZ, Gisele Maria; SILVA, Renata Laudares. Lazer, Turismo, Ecologia: contribuições para uma nova atitude. In: ENCONTRO NACIONAL DE RECREAÇÃ̃O E LAZER, 11., 1999, Foz do Iguaçu, PR. Anais... Foz do Iguaçu, PR: UNIOESTE, 1999. p. 418-422.

TUAN, Yi-Fu. Espaço e Lugar: a Perspectiva de Experiência. São Paulo: Difel, 1983.

Artigo: recebido em 15/08/2008 - aprovado em 08/12/2008 